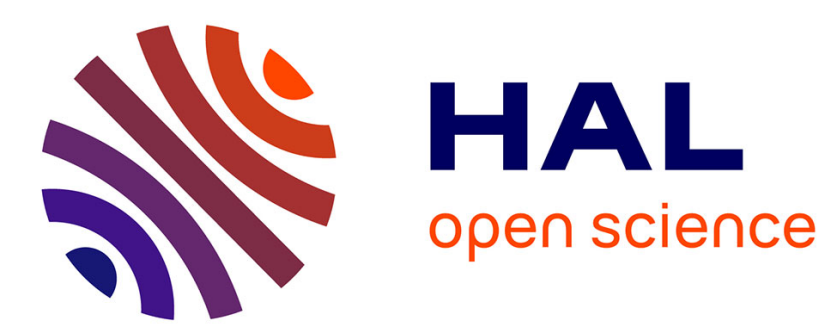

\title{
Physico-chemical limitations during the electrokinetic treatment of a polluted soil
}

Maria Aurora Fernandez, Petra Hlavackova, Véronique Pomes, Michel Sardin

\section{To cite this version:}

Maria Aurora Fernandez, Petra Hlavackova, Véronique Pomes, Michel Sardin. Physico-chemical limitations during the electrokinetic treatment of a polluted soil. Chemical Engineering Journal, 2009, 145 (3), p.355-361. 10.1016/j.cej.2008.05.004 . hal-01845394

\section{HAL Id: hal-01845394 https://hal.science/hal-01845394}

Submitted on 7 Nov 2019

HAL is a multi-disciplinary open access archive for the deposit and dissemination of scientific research documents, whether they are published or not. The documents may come from teaching and research institutions in France or abroad, or from public or private research centers.
L'archive ouverte pluridisciplinaire HAL, est destinée au dépôt et à la diffusion de documents scientifiques de niveau recherche, publiés ou non, émanant des établissements d'enseignement et de recherche français ou étrangers, des laboratoires publics ou privés. 
Review

\title{
Physico-chemical limitations during the electrokinetic treatment of a polluted soil
}

\author{
A. Fernandez ${ }^{\mathrm{a}, *}$, P. Hlavackova ${ }^{\mathrm{a}}$, V. Pomès ${ }^{\mathrm{a}}$, M. Sardin $^{\mathrm{b}}$ \\ a LGPSD-EMAC, Campus Jarlard-Route de Teillet, 81013 Albi CT Cedex 09, France \\ ${ }^{\mathrm{b}}$ LSGC ENSIC, 1 rue Grandville, BP 405 Nancy Cedex, France
}

Keywords:

Electrokinetic

Transport processes

Solid/liquid reactions

Characteristic time

Kaolin

\begin{abstract}
A B S T R A C T
The influence of the ion-exchange solid/liquid reaction on electrokinetic transport phenomena was studied and modelled for a non-permeable porous medium composed of kaolin. Kaolin was selected to model a low-permeable medium, even though it is usually considered to have low ion-exchange capacity and weak selectivity. The influence of this reaction on the characteristic time of the process was demonstrated by studying the lithium $\left(\mathrm{Li}^{+}\right)$electrokinetic transport on a sodium $\left(\mathrm{Na}^{+}\right)$pre-saturated kaolin. Experimental results were obtained using apparatus developed specifically for the study of the electrokinetic transport and which has been well characterized in previous works. The tests were performed by introducing a solution containing $\mathrm{Li}^{+}$at the anode, and measuring the $\mathrm{Na}^{+}$and $\mathrm{Li}^{+}$concentrations at the cathode outlet. Under operating conditions, local equilibrium is assumed in the medium. The equilibrium isotherm of $\mathrm{Li}^{+} / \mathrm{Na}^{+}$exchange was determined by independent experiments on a laboratory column. Ion-exchange equilibrium can be satisfactorily described by a linear isotherm. A theoretical model based on the tanksin-series model was used for modeling the experimental results of the $\mathrm{Li}^{+}$electrokinetic transport. This model considers electro-migration and electro-osmosis as the only transport mechanisms, and takes into account the solid/liquid reaction by a retardation factor, as is usually the case for linear equilibrium models. The comparison between experimental and theoretical results shows that the chemical solid/liquid reaction at least doubles the characteristic time of the transport.
\end{abstract}

\section{Introduction}

Contaminated industrial sites represent considerable danger to the environment and treatment or confinement of these sites is necessary. Polluted soils close to cities represent important economic opportunities for development and, in these cases, confinement is not a viable option. Electrokinetic remediation has been used in the United-States [1] and in the Netherlands [2] for many years, for the treatment of low-permeable soils containing several inorganic (like heavy metals) or organic (like light hydrocarbons) chemical species. Electrokinetic transport includes electrophoresis, electroosmosis and ion migration (electro-migration). These phenomena are provoked by the application of an electrical field to a porous media. For low-permeable soils, electro-osmosis and ion migration are usually considered the most effective mass-transport mechanisms. Electro-osmosis involves water transport at the solid/liquid interface. Electrical forces act on the double layer, which drags

\footnotetext{
* Corresponding author at: INSA Toulouse, Departement GPE, 105 Avenue de Rangueil, 31077 Toulouse Cedex 4, France. Tel.: +33 561559750; fax: +33 561559760. E-mail address: Maria-Aurora.Fernandez@insa-toulouse.fr (A. Fernandez).
}

water towards the opposite electrode. Ion migration is a diffusive transport generated by the electrical forces on ions, which again move to the opposite electrode. Electro-osmosis and ion migration are strongly dependent on the chemical composition of the system [3-5].

In addition to these mechanisms, common mass-transport mechanisms, such as diffusion or convection, and the physical and chemical interactions of the species with the medium also take place. From a physical point of view, for modeling electrokinetic processes common transport mechanisms can usually be neglected: diffusion is very much slower than electrokinetic transport and processes usually concern non-permeable media.

Most publications on electrokinetics are based on experiments carried out at laboratory or pilot-plant scale, with artificially polluted media. Very often, species reactivity is not taken into account, or it is just considered for reactions in liquid phase [6]. Finally, kaolin is often used as a model for a non-permeable medium because of its low adsorption capacity, and solid/liquid (S/L) chemical reactions are usually neglected. As a result, different industrial tests have failed or have obtained mediocre results [7].

Even when the reactions are fast enough to be considered as balanced [8], the electrokinetic process is strongly affected by these 


\begin{tabular}{|c|c|}
\hline \multicolumn{2}{|c|}{ Nomenclature } \\
\hline$c_{\mathrm{e}}, c_{\mathrm{e} i}$ & $\begin{array}{l}\text { theoretical concentration involved in electrokinetic } \\
\text { transport }(\mathrm{M})\end{array}$ \\
\hline$c_{i}$ & solution concentration of the species $i(\mathrm{M})$ \\
\hline$c_{i, \mathrm{C}}, c_{i, \mathrm{~A}}$ & $\begin{array}{l}\text { concentration of the species } i \text { at the electrolytical } \\
\text { compartments }(\mathrm{M})\end{array}$ \\
\hline & $\begin{array}{l}\text { concentration of the species } i \text { in the different parts } \\
\text { of the system } x(\mathrm{M})\end{array}$ \\
\hline \multicolumn{2}{|c|}{$c_{i, 0 C}, c_{i, 0 A} \underset{(\mathrm{M})}{\text { initi }}$} \\
\hline$c_{k}$ & $\begin{array}{l}\text { outlet solution concentration of the species } k \text { in ion- } \\
\text { exchange experiments }(\mathrm{M})\end{array}$ \\
\hline$c_{0}, c_{0 i}$ & feed solution concentration of the species (M) \\
\hline & $\begin{array}{l}\text { diffusion coefficient of species } i \text { in free solution at } \\
\text { infinite dilution }\left(\mathrm{m}^{2} \mathrm{~s}^{-1}\right)\end{array}$ \\
\hline$E$ & electrical field $\left(\mathrm{V} \mathrm{m}^{-1}\right)$ \\
\hline$E^{\circ}$ & standard redox potential (V) \\
\hline$F$ & Faraday's constant $\left(96,485 \mathrm{C} \mathrm{mol}^{-1}\right)$ \\
\hline$\vec{I}$ & electrical current (A) \\
\hline & electrical current density $\left(\mathrm{Am}^{-2}\right)$ \\
\hline$\vec{J}_{i, \mathrm{em}}$ & $\begin{array}{l}\text { mass-flux density by electro-migration of the } \\
\text { species } i\left(\mathrm{~mol} \mathrm{~m}^{-2} \mathrm{~s}^{-1}\right)\end{array}$ \\
\hline$\vec{J}_{i, \text { eо }}$ & $\begin{array}{l}\text { mass-flux density by electro-osmosis of the species } \\
i\left(\mathrm{~mol} \mathrm{~m}^{-2} \mathrm{~s}^{-1}\right)\end{array}$ \\
\hline$k_{\mathrm{eo}}$ & electro-osmotic coefficient $\left(\mathrm{m}^{2} \mathrm{~V}^{-1} \mathrm{~s}^{-1}\right)$ \\
\hline & $\begin{array}{l}\text { equilibrium constant for ion-exchange linear } \\
\text { isotherm }\end{array}$ \\
\hline$M$ & mass of solid in the ion-exchange column ( $\mathrm{g}$ ) \\
\hline$N$ & number of tanks in series used to soil modelling \\
\hline$q, q_{i}$ & $\begin{array}{l}\text { fixed amount of the species } i \text { in } 100 \mathrm{~g} \text { of kaolin (mol } \\
\text { per } 100 \mathrm{~g} \text { kaolin) }\end{array}$ \\
\hline & electro-osmotic flow $\left(\mathrm{m}^{3} \mathrm{~s}^{-1}\right)$ \\
\hline \multicolumn{2}{|c|}{$\begin{array}{c}Q_{f, \mathrm{C}}, Q_{f, \mathrm{~A}} \text { inlet solution flow rates of the electrolytical com- } \\
\text { partments }\left(\mathrm{m}^{3} \mathrm{~s}^{-1}\right)\end{array}$} \\
\hline \multicolumn{2}{|c|}{$\begin{array}{c}Q_{o, \mathrm{C}}, Q_{0, \mathrm{~A}} \text { outlet solution flow rates of the electrolytical com- } \\
\text { partments }\left(\mathrm{m}^{3} \mathrm{~s}^{-1}\right)\end{array}$} \\
\hline$S$ & cross-sectional area for the soil $\left(\mathrm{m}^{2}\right)$ \\
\hline$S_{g}$ & cross-sectional area for the grids $\left(\mathrm{m}^{2}\right)$ \\
\hline$t$ & temps $(s)$ \\
\hline$u_{i}$ & ionic mobility of the species $i\left(\mathrm{~m}^{2} \mathrm{~V}^{-1} \mathrm{~s}^{-1}\right)$ \\
\hline & electro-osmotic velocity $\left(\mathrm{m} \mathrm{s}^{-1}\right)$ \\
\hline$V_{A}, V_{C}$ & volume of the electrolytical compartments $\left(\mathrm{m}^{3}\right)$ \\
\hline & porous volume of the medium in the grids $\left(\mathrm{m}^{3}\right)$ \\
\hline & $\begin{array}{l}\text { porous volume for each elementary volume in } \\
\text { which the soil is divided }\left(\mathrm{m}^{3}\right)\end{array}$ \\
\hline$V_{k}$ & $\begin{array}{l}\text { solution volume in contact with a mass of solid in } \\
\text { ion-exchange column }\left(\mathrm{m}^{3}\right)\end{array}$ \\
\hline$z_{i}$ & charge of the species $i$ \\
\hline \multicolumn{2}{|c|}{ Greek letters } \\
\hline$\varepsilon$ & porosity of the medium \\
\hline & tortuosity of the porous medium \\
\hline$\vec{\nabla} \Phi$ & $\begin{array}{l}\text { electrical potential gradient }\left(\mathrm{V} \mathrm{m}^{-1}\right) \text {. Asterisk }\left({ }^{*}\right) \\
\text { means effective properties in the porous medium. }\end{array}$ \\
\hline
\end{tabular}

chemical reactions, mainly in two ways: the characteristic time of the process is longer and the amount of species recovered is dictated by the chemical reactions. The aim of this work is to illustrate the delay induced on the species transport by the solid/liquid chemical reactions, through an experimental and theoretical work carried out on a model system. The influence of S/L reactions on the time of the process is demonstrated by the study of the lithium
$\left(\mathrm{Li}^{+}\right)$electrokinetic transport on a sodium $\left(\mathrm{Na}^{+}\right)$pre-saturated kaolin.

Experimental results were obtained in an apparatus developed specifically for the study of electrokinetic transport [9]. The tests were performed by introducing a solution containing $\mathrm{Li}^{+}$ at the anode, and measuring the $\mathrm{Na}^{+}$and $\mathrm{Li}^{+}$concentrations at the cathode. $\mathrm{Li}^{+} / \mathrm{Na}^{+}$ion-exchange equilibrium was experimentally determined by independent experiments on a laboratory column, and then modeled. A theoretical model based on the tanks-in-series model was used for modeling the experimental results of the $\mathrm{Li}^{+}$ electrokinetic transport in this reactive system. This model considers electro-migration and electro-osmosis as the only transport mechanisms, and includes the ion-exchange reaction as a process time retardation factor, as is usually the case for linear equilibrium models.

\section{Theoretical basis}

\subsection{Electrokinetic transport phenomena}

The application of an electrical field to a medium generates transport phenomena and also causes chemical reactions at the electrode surfaces, which are responsible, in particular, for the electron exchange between solution and electrical circuit. In a low-permeable porous medium under electrical fields, electro-migration and electro-osmosis are usually considered as the preponderant transport mechanisms. Electrophoresis is usually neglected [6].

\subsubsection{Electro-migration}

The mass-flux density by electro-migration of the species $i, \vec{J}_{i}$, is given by Eq. (1), as a function of the electrical potential applied, $\vec{\nabla} \Phi$. Transport of charge, $\vec{j}=\vec{I} / S$ (Eq. (2)), is also provided by this mechanism because the species concerned are ions [10]:

$\vec{J}_{i, \mathrm{em}}=-\frac{\left|z_{i}\right|}{z_{i}} c_{i} u_{i} \vec{\nabla} \Phi$

$\vec{j}=\frac{\vec{I}}{S}=F \sum_{i} z_{i} \vec{J}_{i, \mathrm{em}}$

where $c_{i}, u_{i}$ and $z_{i}$ are the solution concentration, the ionic mobility and the charge of the species $i$, respectively, $S$ represents the crosssectional area and $F$ is Faraday's constant. Ionic mobility for the species $i$ can be calculated from its diffusion coefficient, $D_{i}[10]$.

In a porous medium, all the transport properties must be corrected (Eq. (3)) in order to take into account the medium structure through its porosity, $\varepsilon$, and tortuosity, $\tau$ [11]:

$$
u_{i}^{*}=\frac{\varepsilon}{\tau} u_{i}
$$

\subsubsection{Electro-osmosis}

The principles of electro-osmosis have been studied from more than a century. The microscopic Helmholtz-Smoluchowski theory is based on the equilibrium between friction and electrical forces in the double layer around particles [12]. Casagrande [13] developed a macroscopic theory based on experimental measurement of electro-osmotic flow for different porous media, by analogy with Darcy's theory of hydraulic conductivity. In this theory, Casagrande showed that a linear relationship exists between the electro-osmotic velocity and the applied electrical potential gradient (Eq. (4)). The proportionality constant $k_{\mathrm{eo}}$ was called the electro-osmotic coefficient, and it can be assumed as constant for quite a wide variety of soils. The electro-osmotic flow, $Q_{e o}$, can be 
calculated from the flow velocity and the cross-sectional area, $S$ :

$\vec{v}_{\mathrm{eo}}=-k_{\mathrm{eo}} \vec{\nabla} \Phi$ and $Q_{\mathrm{eo}}=\left|k_{\mathrm{eo}} \nabla \Phi\right| S$

Values for $k_{\mathrm{eo}}$ determined by Casagrande are between 4 and $6 \times 10^{-9} \mathrm{~m}^{2} \mathrm{~V}^{-1} \mathrm{~s}^{-1}$ for various soils with very different permeability coefficients, from $3 \times 10^{-5}$ to $10^{-13} \mathrm{~m} \mathrm{~s}^{-1}$. In this way, electro-osmosis can be neglected in a permeable media, but can be a significant transport phenomenon for low-permeable soils. In the same way as for other convective transport mechanisms, massflow density for a species $i$ by electro-osmosis can be calculated as

$\vec{J}_{i, \mathrm{eo}}=c_{i} \vec{v}_{\mathrm{eo}}=-c_{i} k_{\mathrm{eo}} \vec{\nabla} \Phi$

Electro-migration and electro-osmosis are the preponderant transport mechanisms in low-permeable media under electrical fields.

\subsection{Electrochemical reactions}

At the interface between the electrodes and the solution, electrochemical reactions take place, with oxidation at the anode and reduction at the cathode. These allow the electrical current to flow continuously in the solution through electron exchange. Most authors consider water electrolysis reactions (with production of $\mathrm{H}^{+}$at the anode and $\mathrm{OH}^{-}$at the cathode) to be the usual electrochemical reactions and they are often the most favourable. However, other reactions can take place spontaneously or can be created to avoid water decomposition (for example, in order to prevent $\mathrm{OH}^{-}$production). For many systems, a thermodynamic prediction of electrochemical reactions can be carried out, based on the determination of the electrochemical potential under working conditions, by application of the Nernst equation for each possible semi-reaction. As a rule, it can be accepted that the species with the lowest potential will be oxidated at the anode, and the species with the highest potential will be reduced at the cathode. This procedure can also be used in order to select a specific product that can be used to avoid spontaneous reactions.

\subsection{Ion-exchange reactions}

Ion exchange involves reactions of ion substitution between a solid surface and a solution in contact with it. Ion-exchange reactions are typically balanced solid/liquid reactions [14]. Equilibrium of ion exchange can be modelled by equations based on the Mass Action Law, but also by using equations based on sorption phenomena, such as Langmuir isotherm which are often used in a purely mathematical approach [15]. In most systems at low concentrations, ion-exchange equilibrium can be represented by a linear isotherm, which implies that the partition of the ion between the solid and the solution is constant. Ion-exchange kinetics is usually governed by internal or external mass transfer as a function of the operating conditions, in particular the relative solid/solution flow rate and the particle size. In this work, ion-exchange reactions were considered at local equilibrium.

\section{Material and methods}

\subsection{Electrokinetic experiments}

The apparatus used for the study of electrokinetic transport consisted of a Plexyglass ${ }^{\circledR}$ cylinder (i.d. $10 \mathrm{~cm}$ ), closed at the extremities by the electrolytical compartments, which were separated by a grid with a filter. The total depth of the soil was $11 \mathrm{~cm}$, including the grids, and the total distance between electrodes was $14 \mathrm{~cm}$. This cell was placed in an experimental set-up that allowed experimental conditions to be controlled, and experimental results to be
Table 1

Experimental conditions used for the electrokinetic experiments

\begin{tabular}{lllll}
\hline Experiment & $\begin{array}{l}c_{\mathrm{Li}, 0 \mathrm{~A}} \\
\left(\times 10^{-2} \mathrm{M}\right)\end{array}$ & $\begin{array}{l}\mathrm{c}_{\mathrm{Na}, 0 \mathrm{~A}} \\
\left(\times 10^{-2} \mathrm{M}\right)\end{array}$ & $\begin{array}{l}Q_{\mathrm{f}, \mathrm{A}} \\
\left(\times 10^{-8} \mathrm{~m}^{3} / \mathrm{s}\right)\end{array}$ & $\begin{array}{l}Q_{\mathrm{f}, \mathrm{C}} \\
\left(\times 10^{-8} \mathrm{~m}^{3} / \mathrm{s}\right)\end{array}$ \\
\hline 1 & 3.7 & 0 & 5.17 & 5.00 \\
2 & 3.0 & 3.0 & 4.07 & 4.85 \\
\hline
\end{tabular}

followed. The electrokinetic cell and the experimental set-up were presented and characterized from a hydrodynamic point of view elsewhere [9]. Analysis by Residential Time Distribution (RTD) [16] showed that the electrolytical compartments could be considered as perfectly mixed, under operating conditions, and that convection could be neglected as a transport mechanism when the cell was placed horizontally.

A commercial kaolin was used as a model medium because of its low permeability. The chemical composition can be basically assimilated to $\mathrm{Si}_{2} \mathrm{Al}_{2} \mathrm{O}_{5}(\mathrm{OH})_{4}$, with traces of $\mathrm{K}^{+}$and $\mathrm{Mg}^{2+}$. Dry density of the powder was $2.6 \mathrm{~kg} \mathrm{~m}^{-3}$, and $90 \%$ of particles were smaller than $10 \mu \mathrm{m}$ (surface distribution) as measured by laser size-distribution measurement [9]. A rigorous procedure was used which allows to guarantee a porosity close to 0.6 for all the experiments. The medium was considered to be saturated (verified during the procedure validation by X-ray tomography) and pre-saturated with a solution of $\mathrm{Na}_{2} \mathrm{SO}_{4} 10^{-2} \mathrm{M}$. So, the $\mathrm{Na}^{+}$was, at the beginning of each test, the free cation in solution. All the experimental procedures for electrokinetic experiments have been explained in a previous article [9].

In this system, experiments were carried out under different operating conditions (Table 1 ). In order to check the validity of the model, different feed solution concentrations of $\mathrm{Na}^{+}$and $\mathrm{Li}^{+}$at the anode have been used. In all the experiments, cationic and anionic flow rates were kept constant and close to $5 \times 10^{-8} \mathrm{~m}^{3} / \mathrm{s}(3 \mathrm{ml} / \mathrm{min})$. These flow rates were considered as a good compromise for electroosmotic flow measurement.

$\mathrm{Li}^{+}$concentration in the initially defined feed solution was $10^{-2} \mathrm{M}$, but in these conditions the electrokinetic cell was very resistive, so the concentrations in the solution were changed in order to have a total solution concentration close to $3 \times 10^{-2} \mathrm{M}$.

The composition of the feed solutions in the electrolytical compartments had to be selected by taking into consideration the electrochemical reactions that would take place, thus avoiding those unfavourable to the system (for instance, the production of $\mathrm{H}^{+}$or $\mathrm{OH}^{-}$, which have higher mobility and can induced secondary chemical reactions with the medium, such as kaolin dissolution). At the cathode, to prevent the production by electrolysis of the $\mathrm{OH}^{-}$, a solution of $\mathrm{K}_{2} \mathrm{~S}_{2} \mathrm{O}_{8}$ (or $\left(\mathrm{NH}_{4}\right)_{2} \mathrm{~S}_{2} \mathrm{O}_{8}$ ) was continuously introduced. At the anode, the introduction of a strong alkali (solutions of $\mathrm{NaOH}$, $\mathrm{LiOH}$, or a mixture of both) at $10^{-1} \mathrm{M}$ prevented the production of $\mathrm{H}^{+}$. In these conditions, the electrolysis reactions that would take place were defined:

$\begin{array}{ll}\mathrm{S}_{2} \mathrm{O}_{8}{ }^{2-}+2 \mathrm{e}^{-} \leftrightarrow 2 \mathrm{SO}_{4}{ }^{2-} & E^{\circ}=2.01 \mathrm{~V} \\ 2 \mathrm{OH}^{-} \leftrightarrow \mathrm{H}_{2} \mathrm{O}+2 \mathrm{e}^{-}+1 / 2 \mathrm{O}_{2} & E^{\circ}=0.40 \mathrm{~V}\end{array}$

Finally, the cations to be studied, $\mathrm{Na}^{+}$or $\mathrm{Li}^{+}$, were fed at the anode would so their transport could be followed through the soil to the cathode by the electrical field. Their concentrations were zero in the cathode feed solution, and were measured by atomic absorption at the cathode outlet solution.

\subsection{Ion-exchange experiments}

Kaolin is one of the simplest argiles and is known to have a low fixed surface charge, usually due to substitutions of ions of similar size but with different charges in their structure [12]. Even 
Table 2

Experimental conditions for cationic concentrations used in ion-exchange tests

\begin{tabular}{lll}
\hline Test & $c_{0} \mathrm{Li}^{+}\left(\times 10^{-3} \mathrm{M}\right)$ & $\mathrm{c}_{0} \mathrm{Na}^{+}\left(\times 10^{-3} \mathrm{MM}\right)$ \\
\hline 1 & 9.4 & 0 \\
2 & 7.5 & 2.7 \\
3 & 5.9 & 4.5 \\
4 & 3.9 & 6.7 \\
\hline
\end{tabular}

though its exchange capacity is very low, it acts as an ion (cationic) exchanger.

The ion exchange of $\mathrm{Li}^{+}$in the $\mathrm{Na}^{+}$pre-saturated kaolin was studied in a laboratory column. The column had an internal diameter of $2.54 \times 10^{-2} \mathrm{~m}$ and the bead was $2.27 \times 10^{-1} \mathrm{~m}$ high. In order to avoid problems due to the low permeability of the medium, kaolin was mixed with glass balls (particle size between 125 and $250 \mu \mathrm{m}$ ), which do not influence $\mathrm{Li}^{+}$retention in the bead. After having been swept by $\mathrm{CO}_{2}$ to ensure saturation, the column was filled with $28.8 \mathrm{~g}$ of kaolin ( $15 \%$ mass). The porous volume, $V_{\mathrm{p}}$, was determined by analysis of Residential Time Distribution (RTD), and shown to be equal to $43 \mathrm{ml}$. The column was determined as very low dispersive. All the experiments were carried out at room temperature.

When prepared, the column was pre-saturated by a solution of $\mathrm{NaCl} 10^{-2} \mathrm{M}$ and fed by solutions containing $\mathrm{LiCl}$ at a precise constant concentration (Table 2). The total concentration of the feed solution was set at $10^{-2} \mathrm{M}$ by addition of $\mathrm{NaCl}$. Changes in $\mathrm{Li}^{+}$concentration at the outlet of the column were continuously monitored by conductimetry. Some samples were also measured by atomic absorption. Tests were carried out in both directions, so the $\mathrm{Li}^{+}$initially fixed in the column (during the adsorption test) was later recovered with a new solution of $\mathrm{NaCl}$ at $10^{-2} \mathrm{M}$ (called the desorption test). We also verified that the hypothesis of local equilibrium was acceptable by adjusting the flow rate of the solution in the column to a value superior to $1.05 \mathrm{ml} / \mathrm{min}$.

Fig. 1 shows an example of the breakthrough curves obtained for adsorption and the corresponding desorption tests, represented as dimensionless $\mathrm{Li}^{+}$outlet concentration as a function of the number of the porous volumes of the solution passed through the column.

From the different tests, the amount of $\mathrm{Li}^{+}$retained by the kaolin can be calculated for the different solution concentrations, $c_{0}$ (Eq. (8)) from the breakthrough curve:

$$
\begin{aligned}
q\left(\frac{\text { mol }}{100 \text { g medium }}\right) & =\sum_{k} \frac{V_{k}}{M}\left(c_{0}-c_{k}\right) \\
& =\frac{100}{M} \sum_{k}\left(\frac{V_{k}}{V_{p}}\right) V_{p}\left(1-\frac{c_{k}}{c_{0}}\right) c_{0}
\end{aligned}
$$

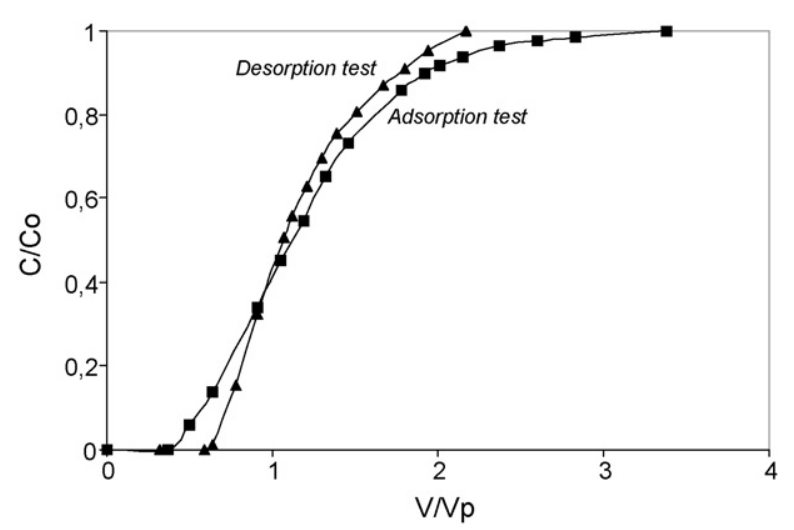

Fig. 1. Breakthrough curve for the exchange of $\mathrm{Li}^{+}$in a $\mathrm{Na}^{+}$pre-saturated kaolin. Adsorption $\left(c_{\mathrm{Li} 0}=9.410^{-3} \mathrm{M}, c_{\mathrm{Na} 0}=0 \mathrm{M}\right)$ and desorption $\left(c_{\mathrm{Li}, 0}=0 \mathrm{M}, c_{\mathrm{Na} 0}=10^{-2} \mathrm{M}\right)$ tests.

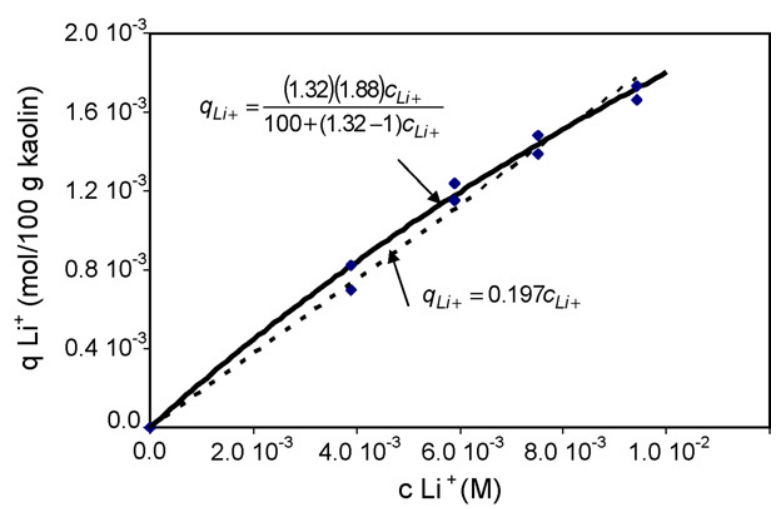

Fig. 2. Isotherm of $\mathrm{Li}^{+} / \mathrm{Na}^{+}$ion exchange on the kaolin at total concentration of $10^{-2} \mathrm{M}$. Experimental (symbols) and theoretical (straight line) results obtained from a Langmuir-type equation (model parameters in the figure) and by considering a linear isotherm $\left(K_{\mathrm{eq}}=1.32 \mathrm{~mol} \mathrm{\textrm {Li } ^ { + }}\right.$ fixed $/ \mathrm{mol} \mathrm{Li}^{+}$in the solution or $0.197 \mathrm{~L}$ of solution/100 g kaolin).

with $q$ is the fixed amount of the species in $100 \mathrm{~g}$ of kaolin, $c_{k}$ the outlet solution concentration of the species after the contact of a solution volume, $V_{k}$, with a mass $M$ of solid in the column; and, $c_{0}$ is the feed solution concentration of the species.

These results of $\mathrm{Li}^{+} / \mathrm{Na}^{+}$ion-exchange equilibrium were modelled by a linear isotherm, with an equilibrium constant $K_{\text {eq }}$ of $1.32 \mathrm{~mol} \mathrm{Li}^{+}$fixed $/ \mathrm{mol} \mathrm{Li}^{+}$in solution. $K_{\text {eq }}$ was calculated by using the equilibrium constant determined by linear regression of the experimental points, and the liquid/solid ratio in the column.

In Fig. 2, the experimental equilibrium curve is represented and compared with two theoretical models, a Langmuir-type equation and a linear model. For the theoretical calcul of the Langmuir equation, a similar value of the equilibrium constant $(1.32 \mathrm{~mol}$

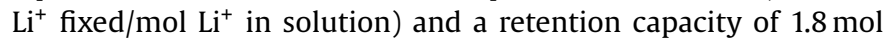
$\mathrm{Li}^{+} / 100 \mathrm{~g}$ kaolin were used. Even though the Langmuir model represents the experimental results somewhat better, the linear model can be considered good enough and its use greatly simplifies the mathematical modelling of transport phenomena, by using the retardation factor $[17,18]$.

This empirical model will be extrapolated to higher concentrations (up to $6 \times 10^{-2} \mathrm{M}$ ), to represent conditions in an electrokinetic cell, even though - as will be shown later - under these conditions the validity of this representation can be questioned.

\section{Modelling of the electrokinetic transport}

The model developed to predict ionic transport in a porous medium under an electrical field is based on the tanks-in-series model [16], where the system is divided into $N$ equal volumes characterized by the homogeneity of the species concentration. In this way, the species concentration in an elementary volume is only a function of time, and it is independent of the spatial variable. The successive resolution of mass balance for each species in the elementary volumes allows prediction of the species concentration at the end of the system, which in practice consists of the electrolytic compartments. As was mentioned before (Section 3), each electrolytic compartment was shown to have a perfectly mixed behaviour, so outlet species concentrations from these compartments can be simulated easily.

Because of the particular geometry of the cell, two different parts must be considered: the "soil" and the "grids". For each part, the corresponding cross-sectional area for mass transport must be considered. Fig. 3 shows a diagram of the modelled system, including the electrolytical compartments. 


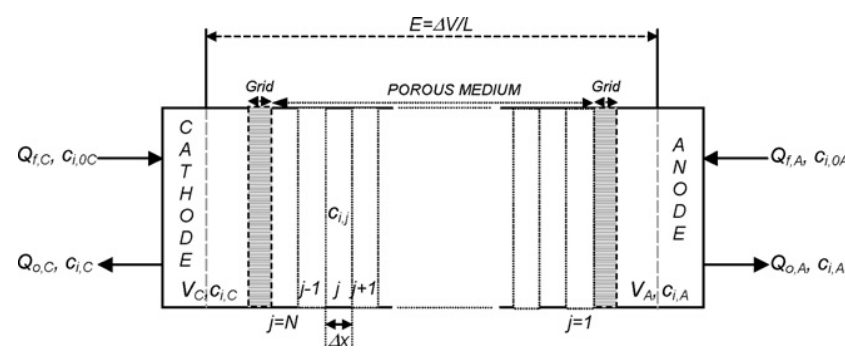

Fig. 3. Description of the experimental system based on the tanks-in-series model.

For a cation, the mass balances in the different parts of the cell are as follows:

- electrolytical compartments

$$
\begin{aligned}
& Q_{f, C} c_{i, 0 C}+Q_{e o} c_{i, \mathrm{~g}}+\nabla \Phi u_{i}^{*} c_{e} S_{\mathrm{g}}-Q_{o, C} c_{i, C} \\
& \quad=V_{C} \frac{\mathrm{d} c_{i, C}}{\mathrm{~d} t} \text { for the cathode }
\end{aligned}
$$

$$
\begin{aligned}
& Q_{f, A} c_{i, 0 A}-Q_{\mathrm{eo}} c_{i, A}-\nabla \Phi u_{i}^{*} c_{e} S_{\mathrm{g}}-Q_{o, A} c_{i, A} \\
& \quad=V_{A} \frac{\mathrm{d} c_{i, A}}{\mathrm{~d} t} \text { for the anode }
\end{aligned}
$$

- porous medium (in the grids)

$$
\nabla \Phi u_{i}^{*}\left(c_{i, N}-c_{i, \mathrm{~g}}\right) S_{\mathrm{g}}+Q_{\mathrm{eo}}\left(c_{i, N}-c_{i, \mathrm{~g}}\right)-V_{\mathrm{g}} \frac{\mathrm{d} q_{i, \mathrm{~g}}}{\mathrm{~d} t}=V_{\mathrm{g}} \frac{\mathrm{d} c_{i, \mathrm{~g}}}{\mathrm{~d} t}
$$

- porous medium (in the soil)

$$
\nabla \Phi u_{i}^{*}\left(c_{i, j-1}-c_{i, j}\right) S+Q_{e o}\left(c_{i, j-1}-c_{i, j}\right)-V_{j} \frac{\mathrm{d} q_{i, j}}{\mathrm{~d} t}=V_{j} \frac{\mathrm{d} c_{i, j}}{\mathrm{~d} t}
$$

In these equations, the electro-osmotic flow $Q_{e o}$ is considered constant, equal for each part of the system (continuity) and, as is usually the case, moving from the anode to the cathode; $\nabla \Phi$ represents the value of the applied electrical potential gradient (which was constant); $u_{i}^{*}$ the effective ionic mobility of the species considered, supposed constant; $S$ and $S_{\mathrm{g}}$ represent the cross-sectional area for the soil and the grids, respectively (constants); $V_{\mathrm{c}}$ and $V_{\mathrm{A}}$ the volumes of the electrolytical compartments; $V_{\mathrm{g}}$ the porous volume of the medium in the grids and $V_{j}$ the porous volume for each elementary volume in which the soil is divided. $Q_{f, \mathrm{C}}, Q_{f, \mathrm{~A}}, Q_{o, \mathrm{C}}, Q_{o, \mathrm{~A}}$ are the inlet and outlet solution flow rates of the electrolytical compartments. For each electrolytical compartment, a relationship exits between the inlet and outlet flow rate and the electro-osmotic flow (Eq. (12a) and (12b)). Finally, $c_{i, x}$ represents the concentration of the species $i$ in the different parts of the system:

$Q_{f, C}+Q_{\text {eo }}=Q_{o, C}$
$Q_{f, A}-Q_{\text {eo }}=Q_{o, A}$

The species concentration at the anode being much greater than that which can be migrated by the electrical field, a theoretical concentration $c_{\mathrm{e}}$ can be defined as the concentration involved in the electrokinetic transport. This concentration can be calculated from Eq. (13) (or Eq. (2)) by using the electroneutrality law (Eq. (14)) (equations are given in scalar form only):

$$
\begin{gathered}
j=F \sum_{i=\text { ions }} z_{i} J_{i, \mathrm{em}}=2 F \sum_{i=\text { cations }} z_{i} J_{i, \mathrm{em}}=2 F\left(u_{i}^{*} c_{\mathrm{e} i} \nabla \Phi\right) \\
\sum_{i=\text { cations }} z_{i} J_{i, \mathrm{em}}=\sum_{i=\text { anions }} z_{i} J_{i, \mathrm{em}}
\end{gathered}
$$

When the mass balances are applied to the medium (or to the grid), they must take into account the amount of the species which reacts, through the variation of the species concentration in the solid, $q_{i, g}$ or $q_{i, j}$, with time. When the hypothesis of local equilibrium can be advanced, the ion-exchange equilibrium relationship allows this amount to be determined, as shown in Eq. (15) for the linear isotherm $[6,17,18]$.

$\frac{\mathrm{d} q_{i}}{\mathrm{~d} t}=\frac{\mathrm{d} q_{i}}{\mathrm{~d} c_{i}} \frac{\mathrm{d} c_{i}}{\mathrm{~d} t}=K_{\mathrm{eq}} \frac{\mathrm{d} c_{i}}{\mathrm{~d} t}$

In this way, mass balance to species $i$, in the grids and in the medium, can be written as

- porous medium (in the grids)

$\nabla \Phi u_{i}^{*}\left(c_{i, N}-c_{i, \mathrm{~g}}\right) S_{\mathrm{g}}+Q_{\mathrm{eo}}\left(c_{i, N}-c_{i, \mathrm{~g}}\right)=V_{\mathrm{g}}\left(1+K_{\mathrm{eq}}\right) \frac{\mathrm{d} c_{i, \mathrm{~g}}}{\mathrm{~d} t}$

- porous medium (in the soil)

$$
\nabla \Phi u_{i}^{*}\left(c_{i, j-1}-c_{i, j}\right) S+Q_{\mathrm{eo}}\left(c_{i, j-1}-c_{i, j}\right)=V_{j}\left(1+K_{\mathrm{eq}}\right) \frac{\mathrm{d} c_{i, j}}{\mathrm{~d} t}
$$

The factor $\left(1+K_{\mathrm{eq}}\right)$ is usually known as the retardation factor, because the process times obtained can be demonstrated to be those without chemical reaction, multiplied by this factor.

The initial conditions for the concentration of the species $i$ in the cell are imposed by the cell pre-saturation protocol (Eq. (18a) and $(18 \mathrm{~b})$ ). At the cathode, the concentrations are 0 . At the anode, the initial concentration for each species depends on the test (see Table 1). During an experiment, the concentration of the species at the anode is imposed by the continuous introduction of the solution. Then, the successive application of the mass balances allows the outlet concentrations to be determined.

At $t=0, \quad c_{i, C}=0 \quad c_{i, A}=$ cte $; \quad c_{i, g}=c_{i, j}=10^{-2} M$;

for $i=\mathrm{Na}^{+}$

At $t=0, \quad c_{i, C}=0 \quad c_{i, A}=$ cte.; $\quad c_{i, \mathrm{~g}}=c_{i, j}=0 \quad$ for $i=\mathrm{Li}^{+}$

\section{Results and discussion: electrokinetic transport in a reactive system}

In Table 3, the parameters used for modelling experiments 1 and 2 are summarized. Most of them are common to both experiments but others, such as porosity, can change slightly from one experiment to another.

Table 3

Parameters used in experiments and for simulations

\begin{tabular}{lll}
\hline Parameter & Experiment 1 & Experiment 2 \\
\hline$\varepsilon$ & 0.60 & 0.55 \\
$\tau$ & 1.3 & 1.3 \\
$u_{\mathrm{Li}}^{*}\left(\mathrm{~m}^{2} \mathrm{~V}^{-1} \mathrm{~s}^{-1}\right)(1)$ & $1.8 \times 10^{-8}$ & $1.1 \times 10^{-8}$ \\
$u_{\mathrm{Na}}^{*}\left(\mathrm{~m}^{2} \mathrm{~V}^{-1} \mathrm{~s}^{-1}\right)(1)$ & $2.2 \times 10^{-8}$ & $2.0 \times 10^{-8}$ \\
$V_{\mathrm{c}}\left(\mathrm{m}^{3}\right)$ & $2.0 \times 10^{-4}$ & $2.1 \times 10^{-4}$ \\
$V_{\mathrm{A}}\left(\mathrm{m}^{3}\right)$ & $2.0 \times 10^{-4}$ & $2.1 \times 10^{-4}$ \\
$V_{\mathrm{g}}\left(\mathrm{m}^{3}\right)$ & $1.5 \times 10^{-5}$ & $1.5 \times 10^{-5}$ \\
$V_{j}\left(\mathrm{~m}^{3}\right)(2)$ & $4.2 \times 10^{-6}$ & $3.8 \times 10^{-6}$ \\
$E\left(\mathrm{~V} \mathrm{~m}^{-1}\right)$ & $2.0 \times 10^{2}$ & $2.0 \times 10^{2}$ \\
$S_{\mathrm{g}}\left(\mathrm{m}^{2}\right)$ & $3.1 \times 10^{-3}$ & $3.1 \times 10^{-3}$ \\
$S\left(\mathrm{~m}^{2}\right)$ & $7.9 \times 10^{-3}$ & $7.9 \times 10^{-3}$ \\
$Q_{\mathrm{eo}}\left(\mathrm{m}^{3} \mathrm{~s}^{-1}\right)(3)$ & $1.0 \times 10^{-8}$ & $1.0 \times 10^{-8}$ \\
$K_{\text {eq }}$ & 1.32 & 1.32 \\
Retardation factor & 2.3 & 2.3
\end{tabular}

(1) Calculated from $u_{i}^{*}=u_{i}^{\infty}(\varepsilon / \tau)$. (2) Estimated from the porosity for $N=110$ perfect mixers. (3) Experimentally measured. 


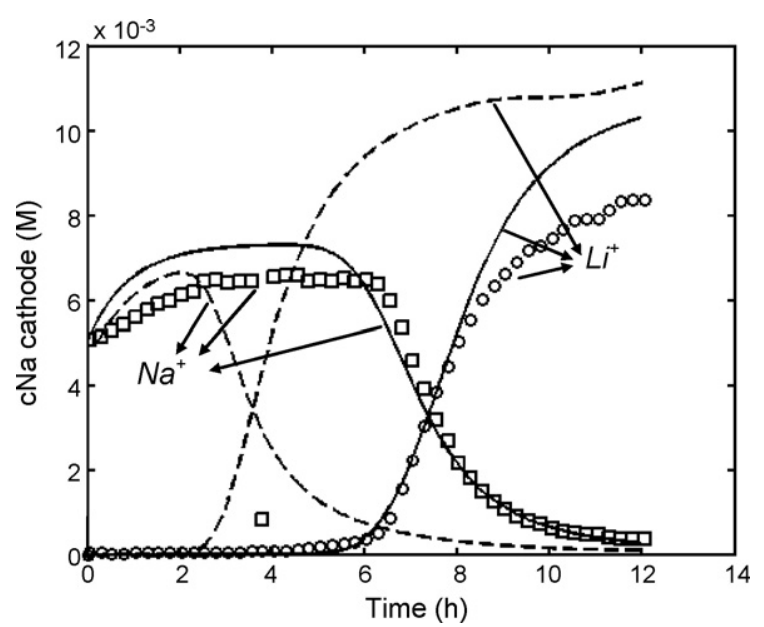

Fig. 4. Changes in the $\mathrm{Na}^{+}$and $\mathrm{Li}^{+}$outlet concentrations at the cathode with time for experiment 1 . Symbols represent experimental results and lines theoretical results obtained considering (straight line), or ignoring (dotted line), their ion exchange on the kaolin.

Figs. 4 and 5 show the changes in cathode outlet concentration for both cations as a function of time, for experiments 1 and 2, respectively. Experimental results are compared with the simulations carried out by considering or ignoring the chemical reaction with the medium. A retardation factor equal to 1 makes simulations without the reaction. Dotted curves represent simulations without considering ion-exchange reaction, and plain curves correspond to simulations which take ion-exchange reaction into account.

Simulations were made by using 110 perfect mixers. That means the transport is not dispersive, and it takes place as a concentration front which moves in the medium. For simulations, the experimentally measured current intensity was used because the conductivity of the medium is continuously changing and their determination is not evident.

In experiment $1\left(\mathrm{Li}^{+}\right.$feed at the anode), the $\mathrm{Na}^{+}$concentration at the cathode increases initially and decreases quickly (as would be the case in a perfect mixer), when the concentration in the medium is exhausted (Fig. 4). $\mathrm{Li}^{+}$, which is introduced at the anode, must go through the medium to reach the cathode, and so its concentration is zero at the beginning of the test, and increases after a time, characteristic for the process under operating conditions.

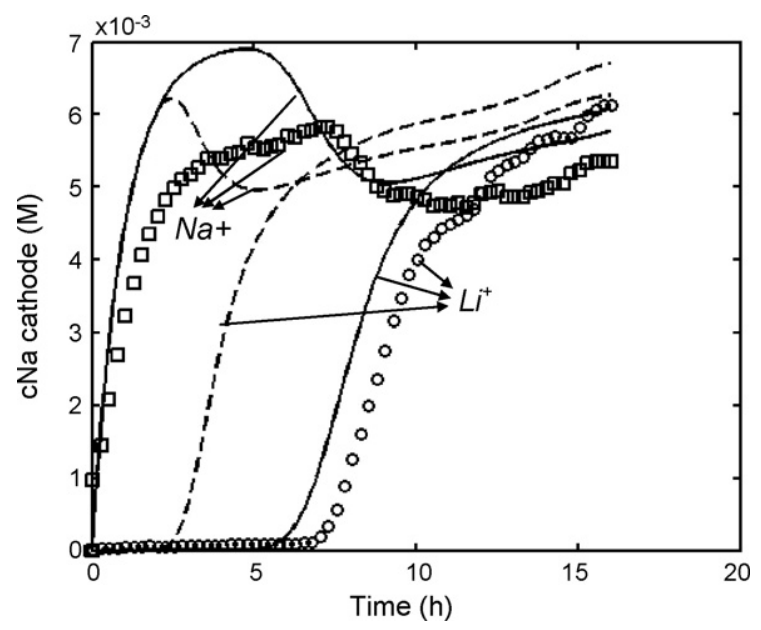

Fig. 5. Changes in the $\mathrm{Na}^{+}$and $\mathrm{Li}^{+}$outlet concentrations at the cathode with time for experiment 2. Symbols represent experimental results and lines theoretical results obtained considering (straight line), or ignoring (dotted line), their ion exchange on the kaolin.
In experiment 2 (Fig. 5), the initial outlet concentration of $\mathrm{Na}^{+}$ increases at the cathode, as in experiment 1 . After a time, the front of the $\mathrm{Li}^{+}$appears at the cathode like as in experiment 1, but that of the $\mathrm{Na}^{+}$is modified because of the introduction of this cation at the anode, at a concentration which establishes their concentration in the medium different from the initial one.

Simulations made taking into account ion-exchange reaction correctly represent the experimental results, and in particular the times of the process, which can be considered as the time for the concentration fronts to appear.

Differences between maximal outlet concentrations of $\mathrm{Li}^{+}$and $\mathrm{Na}^{+}$at the cathode are observed when comparing experimental and theoretical results. In order to explain this difference, various hypotheses can be advanced. One hypothesis concerns the validity of the empirically determined equilibrium isotherm for the total solution concentration used in electrokinetic experiments. Before the apparition of the front concentrations, species concentrations in the medium are increasing: at the beginning of the experiment, the equilibrium isotherm determined must be valuable. However, when solution concentration in the medium comes higher than $10^{-2} \mathrm{M}$, the use of this isotherm can be questioned. Another problem concerns the electro-osmotic flow, which is not constant during the process, even though an average value is used in the model. This affects the calculated outlet flow rate, and thus the theoretical outlet concentrations. Finally, some phenomena, such as molecular diffusion, which is particularly important when the concentration gradients are high (such as in processes with concentration fronts), are neglected in the model.

In any case, for both experiments, the characteristic time of transport phenomena was found to be well represented by the model, and double those without chemical reaction, even when the ion-exchange capacity and the selectivity of the medium were low.

\section{Conclusions}

Electrokinetic transport of $\mathrm{Li}^{+}$and $\mathrm{Na}^{+}$in a model lowpermeable medium was studied in order to analyse the influence of the ion-exchange solid/liquid reaction on the transport. Kaolin was chosen as a medium even though its ion-exchange capacity and selectivity for these cations is low. In the medium, local equilibrium for the $S / L$ reaction was assumed.

The equilibrium isotherm for the $\mathrm{Li}^{+} / \mathrm{Na}^{+}$exchange was determined in a laboratory column, independently from the electrokinetic experiments. The isotherm can be considered as linear from a total concentration up to $10^{-2} \mathrm{M}$, with an equilibrium constant of 1.32. The extrapolation of this empirical equation to higher concentrations seems to be not well adapted to the equilibrium description.

Two tests were carried out using laboratory apparatus with a $\mathrm{Na}^{+}$pre-saturated medium, by introduction at the anode of a solution containing $\mathrm{Li}^{+}$, or both $\mathrm{Li}^{+}$and $\mathrm{Na}^{+}$. The experimental results were modelled using the tanks-in-series model, and assuming the electrolytical compartments to be perfectly mixed. The outlet concentrations for cations were not always accurately predicted by the model, but the time of the process (assimilated to the time for the apparition of the concentration fronts) was well predicted.

Characteristic times of electrokinetic transport phenomena are almost double when a chemical reaction with the medium takes place. They can be correctly modelled by the use of a retardation factor, which is a function of the equilibrium constant. The application of the electrokinetic processes in order to treat media where a sorption of pollutant can be possible must consider this retard in order to predict treatment times correctly. 


\section{References}

[1] Y.B. Acar, R.J. Gale, A.N. Alshawabkeh, R.E. Marks, S. Puppala, M. Bricka, R. Parker, Electrokinetic remediation: basics and technology status, J. Hazard. Mater. 40 (1995) 117-137.

[2] R. Lageman, Electroreclamation: applications in the Netherlands, Environ. Sci. Technol. 27 (13) (1993) 2648-2650.

[3] G.R. Eykholt, D.E. Daniel, Impact of system chemistry on electroosmosis in contaminated soil, J. Geotechnol. Eng. 120 (5) (1994) 797-815.

[4] E.R. Lindgren, R.R. Rao, B.A. Finlayson, Numerical simulation of electrokinetic phenomena, A. C. S. Symp. Ser. 607 (1995) 48-62.

[5] J.M. Dzenitis, Soil chemistry effects and flow prediction in electroremediation of soil, Environ. Sci. Technol. 31 (1997) 1191-1197.

[6] J.W. Yu, I. Neretnieks, Modelling of transport and reaction processes in porous medium in an electrical field, Chem. Eng. Sci. 51 (19) (1996) 43554368.

[7] EPA, Technology Alternatives for the Remediation of Soils Contaminated with As, Cd, Cr, Hg and Pb - Engineering Bulletin - Rapport EPA/540/s-97/500, 1997.

[8] R.A. Jacobs, R.F. Probstein, Two-dimensional modeling of electroremediation, AIChE J. 42 (6) (1996) 1685-1696.
[9] V. Pomès, A. Fernandez, D. Houi, Characteristic time determination for transport phenomena during the electrokinetic treatment of a porous media, Chem. Eng. J. 87 (2002) 251-260.

[10] J.S. Newman, Electrochemical Systems, 2nd ed., Prentice Hall, Englewood Cliffs, NJ, 1991.

[11] J.Villermaux, Génie de la réaction chimique. Conception et fonctionnement des réacteurs, 2nd ed., Tec\&Doc Lavoisier, Paris, 1993.

[12] J.K. Mitchell, Fundamentals of Soil Behaviour, 2nd ed., John Wiley, New York, 1993.

[13] L. Casagrande, Electro-osmosis in soils, Geotechnique 1 (3) (1939) 159-177.

[14] F. Helfferich, Ion Exchange, McGraw-Hill, New York, 1962.

[15] A. Fernandez, G. Carta, Characterization of protein adsorption by composite silica-polyacrylamide gel anion exchangers. I. Equilibrium and mass transfer in agitated contactors, J. Chromatogr. A 746 (1996) 169-183.

[16] O. Levenspiel, Chemical Reaction Engineering, John Wiley \& Sons, New York, 1962.

[17] J. Villermaux, W.P.M. Van Swaaij, Modèle représentatif de la distribution de temps de séjour dans un réacteur semi-infini à dispersion axiale avec zones stagnantes, Chem. Eng. Sci. 24 (1969) 1097-1111.

[18] C.D. Shackelford, D.E. Daniel, Diffusion in saturated soil. I. Background, J. Geotechnol. Eng. 117 (3) (1991) 467-484. 